\title{
semiótica, enunciacẹTo e polifonia
}

\author{
Luiz Tatit
}

Professor na FFLCH - USI*

\begin{abstract}
This paper examines the evolution of the main text and discourse theories in recent times, by comparing it with the advances which occurred in semiotics in the field of enunciation. After studying the ideas of "interdiscursivily" and of "poliphonic discourse" - essential within the scope of these theories - the author still proposes a semiotic development of the concept of discursive "voices" by assigning to it a narrative and tensive basis, with the purpose of creating subsidies for the scientific improvement of the analytical procedures which arc commonly used.
\end{abstract}

KEY WORDS: Discourse - Semiotics - Enunciation - Intertextualily.

Quando Saussure atribuiu à linguagem (língua e fala) um caráter, a um só tempo, "multiforme" e "heteróelito" certamente nào poderia imaginar que, quase um śsculo depois, sua formulação encontraria uma ressonância sem precedentes - mas, provavelmente, menor do que ainda terá no futuro - expressa na pluralidade de linhas de pesquisa dedicadas não apenas aos tradicionais estudos fonológicos, morfológicos e frasais mas, sobretudo, ao domínio do discurso e dos processos enunciativos. Mesmo que algumas linhas devam pouco à herança saussuriana, não há como negar que a pertinência de tantos enfoques sobre o mesmo objeto lato sensu, a linguagem, só vem confirmar os traços de complexidade que o lingüista suíço atribuiu a seu tema.

$\mathrm{Na}$ realidade, apenas uma das diversas teorias que hoje se dedicam à abordagem do discurso $\mathrm{c}$ do texto pode ser considerada inteira- 
mente comprometida com os princípios do pensamento saussuriano. Trata-se da semiótica (de Greimas), já definida como Escola de Paris (COQUET, 1982), que, embora tenha bebido em fontes antropológicas (Lévi-Strauss, Propp) c fcnomcnológicas (Merleau-Ponty), jamais deixou de reconhecer sua dívida principal com o projeto científico globalizado de Hjelmslev, erigido, por sua vez, sob a metodologia da lingüística de Saussure. As incursões pioneiras de teóricos também vinculados à lingüística estrutural, como R. Jakobson e E. Benvenistc, nos estudos enunciativos e as análises narrativas $\mathrm{c}$ discursivas reconhecidamente originais de nomes como R. Barthes, T. Todorov, Genette ou J. Kristeva, todos tributários de algum modo a Saussure, abriram, sem dúvida, muitas frentes de pesquisa no domínio do discurso, mas não se pode dizèr que tenham criado as condições epistemológicas e metodológicas para a construção de uma verdadeira teoria do discurso, em que a recuperação coerente e progressiva da competência do sujeito de enunciação correspondesse ao próprio desvendamento do sentido.

Evidente que pensamos tal teoria no quadro de uma formalização que ofereça subsídios pouco mais científicos à abordagem interpretativa. A possibilidade de categorização, ainda que parcial, das línguas naturais, dentro da concepção de que "línguci é forma e não substância ${ }^{55}$ restringiu, durante muito tempo, o campo da pesquisa européia às unidades fonológicas e morfológicas, traçando como limite máximo de pertinência lingüística o nível da frase. Esse estágio foi registrado por Benvenistc em célebre artigo que considerava a passagem do nível frasal ao nível discursivo como correlata à passagem da língua, enquanto sistema de significação, ao uso lingüístico, enquanto processo de comunicação (BENVENISTE, 1976: 127-140).

Oricntando-sc por uma tradição totalmente diversa - embora sempre no interior da episteme estruturalista -, cm que contrastavam abordagens "*puramente" lingüísticas (Bloomfield) com tendências antropológicas e interdisciplinarcs (Sapir), a lingüística norte-americana deste século também cultivou uma forte expectativa de formalização, realizada, em grande medida, nos modelos gramaticais construídos por N. Chomsky e seus continuadores. Nesse caso, mais que limite para a investigação lin- 
güística, o nível da frase passou a ser a dimensão privilegiada para a implantação de uma sintaxe gcrativa e transfomiacional que pudesse responder pelas condições formais de produção do som e do sentido.

\section{Teorias do Texto e do Discurso}

Quase todas as teorias de análise dos textos c dos discursos surgiram, evidentemente, de uma descrença dos métodos de formalização quando se trata de investigar o sentido engendrado no interior das atividades discursivas. De fato, as leis sintáxicas que regem a dimensão frásica reduzem-se a funções meramente localizadas toda vez que o enfoque se desloca para o âmbito da mensagem global do texto. A relevância dos aspectos semânticos, a intencionalidadc do sujeito, os conteúdos implícitos, os acordos c desacordos entre cnunciadorcs, essas e outras questões colaboram no sentido de restringir ainda mais a importância dos elementos puramente sintáxicos, mesmo no nível dos pequenos enunciados.

Estabelecendo a oposição entre frase e enunciado c acrescentando às formalizações propostas para a primeira uma dimensão teórica comprometida especialmente com o sentido produzido pelo segundo, os pesquisadores dos discursos e dos textos fundaram princípios c métodos que, no nosso entender, oscilam entre dois enfoques interdependentes. De um lado, os lingüistas buscam elementos para a abordagem dos fenômenos de interdiscursividadc, intertextualidade, heterogeneidade discursiva ou, ainda, de polifonia. De outro, não podem deixar de preocupar-se também com os fatores de coesão e de coerência discursiva e textual. No primeiro caso, a adoção progressiva de uma interdisciplinaridadc - que vai da sociologia à psicanálise, passando por domínios da filosofia e da inteligência artificial -, acaba, por vezes, conduzindo a pesquisa para fora da órbita propriamente lingüística, de modo que o texto toma-se apenas pretexto para uma verdadeira compulsão interpretativa. No segundo caso, a concentração excessiva sobre os fenômenos que garantem a coerência do discurso - as anáforas, os conectores de frases, os dêiticos, as pressuposições, as tematizações, as modalizações, os marcadores convcrsacionais etc. - muitas vezes caminha para uma gramaticalização do texto, com 
regras $\mathrm{dc}$ reconhecimento $\mathrm{c}$ aceitabilidade completamente inadequadas a essa dimensão dc análise.

Atentos, geralmente, a essas polarizações, os teóricos do discurso que endereçam seu gesto inicial para a polifonia c a interdisciplinaridadc, como O. Ducrot c D. Maingueneau, por exemplo, acabam dedicando as fases intermediárias da pesquisa à busca de coerência lingüística. Em contrapartida, os teóricos de tradição chomskiana, como Fillmore e Van Dijk, por exemplo, que partem da necessidade de constituir uma gramática de geração textual, se vêem ás voltas com a amplitude das situações comunicativas e terminam por criar uma instância dc interpretação pragmática, levando em conta interação, crenças, desejos, preferências c valores em geral dos enunciadorcs.

\section{A Abordagem Semiótica}

A semiótica, por sua vez, vem progredindo no sentido de criar condições teóricas para abordar os fenômenos polifónicos e interdiscursivos - considerados todos como fenômenos de enunciação sob a égide da coerência sintáxica fornecida pelas estruturas sêmio-narrativas, as mesmas que dão conta da organização do enunciado.

Em artigo publicado no primeiro número desta revista, Greimas traça as principais diretrizes epistemológicas para uma abordagem formal da enunciação (GREIMAS, 1974: 9-25). Preocupado com a possibilidade de reinstauração de um sujeito ontológico na instância enunciativa, o semioticista insiste no princípio de reconstrução dessa instância única c exclusivamente pelo que é dito ou extraído por pressuposição lógica do texto. Trata-se, nesse sentido, dc descrever, além do próprio enunciado, a enunciação enunciada. Para o autor, tudo deve se fundamentar no texto e, fora dele, "não há salvação" Isso diz respeito a qualquer enfoque que pretenda abordar cientificamente a questão enunciativa.

A semiótica desenvolveu esses postulados de Greimas esclarecendo, cada vez mais, a diferença entre enunciação pressuposta, aquela que subjaz necessariamente ao texto independentemente dc marcas indicativas, e enunciação enunciada que corresponde a uma espécie dc simulacro da 
cnunciação no interior do texto (GREIMAS e COURTÉS, 1979- 128). Entre os dois tipos de cnunciação temos uma relação metafórica na medida $\mathrm{cm}$ que há uma pretensa similaridade entre eles. Tal similaridade, entretanto, jamais poderá ser comprovada, pois só sabemos do primeiro tipo pelo segundo. Mas quando consideramos a cnunciação enunciada como uma "subclassc de enunciados" ao lado dos demais, recuperamos a mesma relação mctonímica que faz de todo enunciado um componente da cnunciação. Assim, as marcas enunciativas, que funcionam como manifestação da metalinguagem descritiva no texto, somadas a todos os outros enunciados desse mesmo texto representam a vasta competência enunciativa do sujeito discursivo.

Tal competência enunciativa lato sensu pode ser desmembrada em competências particulares. Regendo seus enunciados gerais, a cnunciação atualiza todas as etapas do percurso gerativo, desde as estruturas sêmionarrativas e as estruturas discursivas (onde as operações narrativas são proccssualizadas no tempo e no espaço) até as estruturas textuais (onde, em contato com o plano da expressão, os discursos tomam uma configuração substancial: linearidade, planaridade, bidimensionalidade, etc.). (GREIMAS c COURTÉS, 1979: 127). Portanto, a cnunciação atualiza, pelo menos, essas três competências - narrativa, discursiva e textual - na produção de seus enunciados. Ampliando esse modelo, M. Hammad analisou a presença da cnunciação enunciada, na forma da permanência de um contrato EU-TU, ao lado dos enunciados, nas três etapas do percurso gerativo canônico (HAMMAD, 1983: 35-46).

Todos esses progressos (c outros não-mencionados) podem ser vistos como decorrência da partição proposta por Bcnvcniste para a categoria "pessoa" cm termo marcado pela subjetividade (EU-TU) e termo nãomarcado (ELE). Ao primeiro, a semiótica fez corresponder a noção de cnunciação enunciada. Ao segundo, simplesmente, enunciado. Quando o cnunciador projeta no texto um narrador que fala em primeira pessoa (virtualizando, portanto, um narratário $\mathrm{cm}$ segunda pessoa), instruindo de maneira privilegiada a cnunciação enunciada, temos um caso de ciebreagem enunciativa. Esse processo é enriquecido, geralmente, com as projeções simultâneas das categorias do tempo c do espaço em suas 
formas também presentificadas: agora c aqui respectivamente. Quando o enunciador relata o texto em terceira pessoa, tentando substituir a subjetividade da enunciação pela objetividade do enunciado, a interlocução ć anulada c temos o procedimento da debreagem eminciva.

Seguindo a mesma orientação, as projeções de tempo e espaço também produzem um desengate da instância enunciativa, configurándose num então e num alhures próprios do enunciado. Alternando debreagens enunciativas e debreagens enuncivas, o enunciador promove em seu texto efeitos de "verdade", responsáveis, em grande medida, por sua eficácia. As debreagens de primeiro grau (narrador/narratário), de segundo (interlocutor/interlocutário) e assim sucessivamente, produzem a impressão de situação locutiva real (caso dos diálogos internos ao discurso). As debreagens enuncivas, restaurando um relato no interior do diálogo, refcrcncializa tal diálogo (GREIMAS c COURTÉS, 1979: 80).

Depois desses estudos concementes ao plano discursivo de superfície, a semiótica deu um novo estatuto à relação enunciador/enunciatário, integrando-a como parte do modelo narratológico geral. Se a enunciação pode ser considerada um ato como outro qualquer, em que há produção e comunicação do objeto "discurso" (LANDOWSKI, 1983: 78), enunciador c cnunciatário reproduzem a relação destinador/destinatário que, no esquema narrativo canônico, define a fase persuasivo-manipulatória anterior à ação propriamente dita. Com esse gesto, além da semiotização de um conceito tradicionalmente refratário à formalização, os pesquisadores puderam definir os papéis actanciais dos dois sujeitos enunciativos (sujeito da persuasão e sujeito da interpretação) e, principalmente, a natureza discursiva do /fazer/ do cnunciador-destinador (fazer persuasivo). Conseqüentemente, o cnunciatário-destinatário, exercendo seu /fazer/ interpretativo, poderá aceitar ou rejeitar a relação persuasivo-manipulatória, desencadeando ou não outros fazeres e outros discursos (BARROS, 1988: 92-93).

\section{Persuasão, Argumentação e Polifonia}

Para que a persuasão e a manipulação se efetivem, um primeiro contrato, de natureza fíduciária, deve ser firmado entre destinador c des- 
tinatário no sentido de entrarem em acordo quanto aos valores que serão trocados ou comunicados. Embora tal contrato seja, em geral, estabelecido em simultancidadc com a comunicação entre os actantes, seu estatuto de pressuposto lógico c inégável.

O estudo dessa fase de persuasão c de cultivo da relação de confiança tem chamado a atenção da semiótica para os mecanismos de argumentação formulados por filósofos ou lingüistas em suas pesquisas paralelas. É o caso, por exemplo, de Ducrot, Pêchcux, Mainguencau c Searle entre outros que, embora abordem questões de natureza bem diversa da semiótica, incidem, de algum modo, sobre o tema do acordo entre enunciador e enunciatário em relação aos seus valores, sobre as transformações de opinião c sobre a assimilação do novo no quadro do já conhecido e acreditado (o reconhecimento) (BARROS, 1988: 112). $\mathrm{N}$,

De acordo com a metodologia de Ducrot, a frase é apenas uma entidade teórica responsável pela significação mas pouco relacionada com o sentido do discurso. Este pertence à esfera do enunciado, que traz consigo todas as qualificações necessárias para se estabelecerem os elos de continuidade entre os demais enunciados de um discurso. Cabe à "pragmática semântica" portanto, dar conta desses enunciados produzidos pela fala, identificando aí as vozes de enunciadores que correspondem aos diversos pontos de vista veiculados por uma locução.

Para explicar sua concepção de polifonia do discurso, Ducrot se utiliza de um modelo teatral. Associa, primeiramente, o autor (ou narrador) da peça à noção de "locutor" do enunciado. Em seguida, identifica os personagens $\mathrm{e}$ as diversas vozes que integram o espetáculo com os enunciadores cujos diferentes enfoques respondem pela heterogencidade da cnunciação (DUCROT, 1987: 161-218).

Mesmo mantendo suas pesquisas num terreno eminentemente lingüístico, Ducrot não deixa de convocar a força precursora de M. Bakhtin que sempre chamou a atenção dos estruturalistas c formalistas para a "presença do outro" nos discursos aparentemente atribuídos a um só sujeito. A cnunciação em Bakhtin sempre teve um caráter dialógico em 
que as vozes - a polifonia - aparecem como verdadeiras máscaras carnavalescas a serem desvendadas pelo processo descritivo.

Pêcheux, por sua vez, considera uma inevitável "tensão entre descrição e interpretação no interior da análise do discurso " (PÊCHEUX, 1990: 19), uma vez que o sentido pressupõe uma estrutura lingüística de apoio mas só se define, de fato, no âmbito do confronto entre as formações ideológicas de seus locutores. A influência de Althusser e Foucault na teoria de Pêcheux revela-se determinante quando este autor reconhece o sujeito como um produto da formação discursiva e ideológica da qual se julga produtor. A própria tentativa de fazer do discurso um espaço monofônico já constitui, em sua visão de origem marxista, um sintoma ideológico de camuflagem inconsciente da própria formação discursiva. Todo sujeito, em princípio, pretende exercitar sua liberdade enunciativa, formulando idéias originais e coerentes que, no entanto, esbarram no caráter eminentemente polifónico e remissivo de qualquer discurso, provocando, ao mesmo tempo, efeitos de atividade (sujeito propriamente dito) e de passividade (assujeitamento). Refletindo sobre os trabalhos que, na linha de Pêcheux, trazem elementos para se pensar a subjetividade, Helena Brandão, a partir também de Orlandi e Guimarães, define o sujeito, na Análise do Discurso, como uma entidade

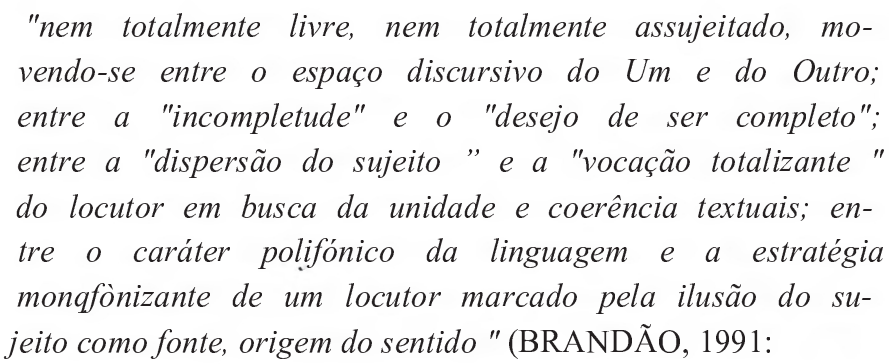

Essa estratégia monofonizante pode, por outro lado, incorporar a polifonia, fazendo com que as sucessivas alusões a outros campos discursivos concorram para melhorar a eficácia da comunicação. E tudo reverte-se então para o sujeito enunciativo e sua capacidade de suscitar a 


\section{Luiz Tatit}

adesão de seus interlocutores, já que o efeito de verdade provém justamente da possibilidade de instruir, de vários ângulos, o valor da mensagem principal. Essa questão da eficácia dos discursos é abordada por Maingueneau que só concebe (um plano para) o estabelecimento de regras discursivas na relação do sujeito com o outro num espaço interativo. Para esse autor, o discurso se constrói como um "exercício de polêmica" praticado no intervalo entre as posições enunciativas (MAINGUENEAU, 1989: 117. 120 e 125).

Interessante observar que todos esses teóricos da Análise do Discurso - não apenas Ducrot, Pêcheux e Maingueneau, mas outros como Perelman ou mesmo filósofos da linguagem como Austin e Searle - consideram a dimensão estratégica do discurso evidenciada nas práticas corriqueiras de conquista da adesão do interlocutor. Consciente ou inconscientemente, os casos de polifonia e interdiscursividade contribuem, cm geral, para a eficácia da comunicação, c tomamos comunicação aqui em sua acepção mais ampla possível: como atividade produtora de relações polêmicas ou relações contratuais.

No primeiro caso, e de acordo com Maingueneau,

"o exercício da polemica presume a partilha do mesmo campo discursivo e das leis que the estão associadas. É preciso desqualificar o adversário, custe o que custar, porque ele é constituído exatamente do Mesmo que nós, mas deformado, invertido, conseqüentemente insuportável " (MAINGUENEAU, 1989: 125).

Basta, por exemplo, que se recuse algum aspecto considerado pressuposto pelo interlocutor e teremos alta probabilidade de desencadear um discurso hostil que, certamente, não levará em conta a ampla faixa de consenso subjacente à conversação. Nesse caso, evidentemente, há interesse em se prolongar o estado de desacordo como parte de uma estratégia geral de valorização das descontinuidades.

Ora, no âmbito da teoria semiótica, uma tal descontinuidade entre sujeitos define movimentos narrativos antagônicos em que sujeito e anti- 
sujeito põem $\mathrm{cm}$ destaque os pontos de desigualdade de suas respectivas competências e. sempre num plano cognitivo, rejeitam os papéis de destinador e destinatário da comunicação. Esta só se inicia efetivamente com os primeiros indícios de estabelecimento de contrato. Daí a importância das estratégias persuasivas e das conquistas fiduciárias que destacamos acima. É a partir desse contrato, cm vias de se firmar, que podemos determinar o lugar modal da manipulação.

Só depois de bem-caracterizadas as noções complementares de fazer persuasivo e fazer interpretativo, como articulação "coringa" presente em todas as etapas do modelo narrativo, o lugar de investigação da comunicação enunciativa pode ser devidamente delimitado. Afinal, o enunciador é, para a semiótica, um destinador de objetos cognitivos ou. mais rigorosamente, um destinador - ou ainda um actante de comunicação - que visa persuadir o destinatário (enunciatário), através da conquista de sua confiança.

Grcimas já apontou, com argúcia, a presença e até a necessidade da fidúcia no plano do fazer interpretativo. O ato de crer (ato epistêmico) é definido como solicitação de consenso, pressuposto necessário à persuasão propriamente dita $\mathrm{c}$ à manipulação no nível semio-narrativo. Como o ato epistêmico é um ato interpretativo, sua verificação no domínio da sanção, pólo de interpretação limite do esquema narrativo, tem um rendimento especial que pode ser extrapolado para as demais etapas narrativas. Quando o destinador julgador sanciona o percurso do sujeito, reconhecendo suas qualidades de "herói" c desmascarando o anti-sujeito "vilão" está, cm nível mais profundo, pondo fỉm na crise de confiança instalada na sociedade, a respeito de quem é quem, quem é sincero, quem mente, enfim, sobre qual é o discurso da verdade para a axiologia vigente (GREIMAS, 1981: 24). E quando dizemos que o destinador julgador reconhece o sujeito e sua performance, a noção de "reconhecer" é pertinente por ser mais uma dimensão do ato epistêmico. Trata-se de uma "operação de comparação" entre o que é proposto pelo sujeito e aquilo que o destinador julgador já conhece (e crê) dentro de sua episteme. O reconhecimento para Grcimas é um controle de adequação do desconhecido no já conhecido e assimilado. Diante do reconhecimento, as noções 


\section{Luiz Tatit}

de verdade (ser/parecer) ou falsidade (não ser/não parecer) da proposição ou do percurso do sujeito nem vêm ao caso. A adequação do novo ao já conhecido determinará o possível êxito ou fracasso do processo persuasivo (GRE1MAS, 1983: 119).

“(...) si Ia communication $n$ 'est pas un simple transfert $d u$ savoir, mais une entreprise de persuasion et d'interprétation située à l'intérieur d'une structure polémico-contractuelle, elle se fonde sur la relation fiduciaire dominée par les instances plus explicites du fairecroire et du croire, où la confiance dans les hommes et dans leur dire compte certainement plus que les phrases "bien faites " ou leur vérité conçue comme une référence extérieure" (GREIMAS, 1983: 17).

Portanto, todos esses novos dispositivos - ato epistômico, contrato fiduciário, processo persuasivo/interpretativo - inauguram um viés para a análise da comunicação intersubjetiva c para a consideração das informações transmitidas como objetos cognitivos em circulação. São os requisitos iniciais para uma semiotização da enunciação, para a ordenação sintáxica dos interlocutores em estruturas narrativas, $\mathrm{cm}$ que podem ser relacionados $\mathrm{cm}$ função das respectivas competências modais - desigualdade de competência justificando, em parte, os desvios dc entendimento e os ímpetos de dominação (GREIMAS, 1983: 11).

Para a descrição semiótica, não há nada mais promissor do que a possibilidade de ordenar o contexto enunciativo numa narratividade paralela á do enunciado. Funciona à maneira do effet de miroir definido por HAMMAD (1983: 41). Como se a enunciação reproduzisse, em macroestrutura. as articulações do enunciado. Daí o uso pleonástico que esse autor faz das noções de enunciação e enunciado. Faz questão de frisar que se trata de uma "enunciação enunciada" ao lado do "enunciado enunciado", em que o último representa um objeto de valor posto em circulação pelo enunciador. A enunciação enunciada passa a ser o programa narrativo de base, numa dimensão integralmente cognitivofiduciária, enquanto os programas narrativos do enunciado enunciado 
operam como programas de uso. Os chamados interlocutores naõ o são mais em termos de "realidade" mas sim enquanto actantes competentes, modal e temáticamente, que podem interagir em bases persuasivas e manipulatórias (LANDOWSKI, 1983: 15).

\section{Semiotização das Vozes Discursivas}

A sintaxe narrativa tem por fundamento a categoria juntiva, urna espécie de fusão primordial entre actantes, que se manifesta ora pela negação desse princípio, ou seja, pela disjunção subjetal ou objetai, ora pela reabilitação dos vínculos nas formas conjuntivas que reintegram o sujeito no mundo natural e na sociedade. A descontinuidade na relação subjetal gera os actantes sujeito/anti-sujeito; na relação objetai, os actantes sujeito/objeto. A continuidade na relação subjetal gera os actantes destinador / destinatário enquanto na relação objetai gera os tradicionais conceitos de sujeito e objeto (ZILBERBERG, 1988: 107).

Com esses actantes - que são puras funções relacionais (daí a noção de estruturas narrativas)-.a semiótica propõe etapas lógicas conhecidas como persuasão-manipulação, paixão-ação e sanção.

A primeira é a etapa de comunicação por excelência, na qual os sujeitos oscilam entre relações polêmicas e relações contratuais, formulando estratégias discursivas de persuasão (fazer-crer) e de manipulação (fazer-fazer). Se a seleção das operações descontínuas prevalece e. com ela. as relações polêmicas, a própria condição para a narrativa - um mínimo de consenso entre dois sujeitos - se encontra ameaçada, uma vez que, não havendo destinatário, não há também a função de sujeito do /fazer/. Por isso, nessa etapa, devem ser estudados todos os recursos argumentativos que visam obter a adesão do interlocutor. Trata-se, no fundo, de um processo delicado de avaliação dos valores e ssupostos comunitários que subjazem à comunicação. Se há predominância das operações contínuas c das relações contratuais, o êxito das estratégias persuasivas pode ser aferido pela circulação desimpedida dos valores e dos conteúdos entre destinador e destinatário e pela instituição deste último em sujeito do /querer/ ou do /dever/ fazer. 


\section{Luiz Tatit}

A segunda etapa compreende unía fase de transição entre as relações subjetais c as relações objetais, em que o sujeito enquanto /ser/ avalia sua competência e suas carências, ainda sofrendo efeitos da relação com o destinador, mas, de qualquer fomia, procurando se posicionar em função do objeto. Tal estado, típico da fase passional, define o sujeito por sua disjunção espacial com o objeto de valor, nías, por outro lado, por sua conjunção temporal com esse mesmo objeto manifestada na noção de espera. A fase correspondente à ação propriamente dita (ao fazer) pressupõe a superação da fase passional c uma constante interação com o /saber/ c o /poder/ do destinador, pois dessas modalidades depende a formação plena da competência do sujeito. O sujeito competente equivale ao sujeito que realiza sua performance e conquista seu objeto. Fora disso c scni o auxílio constante do destinador, o sujeito, muitas vezes, não consegue identificar seu objeto, até porque não tem condições cpistêmicas de reconhecer os seus valores.

A última etapa do esquema geral da narrativa prevê o restabelecimento dos valores comunitários, agora por meio da função de destinador julgador. Este actante opera com as modalidades vcridictórias e extrai de suas articulações no quadrado semiótico as noções de verdadeiro (ser + parecer), de falso (não ser + não parecer), de ilusório (parecer + não ser) e de secreto (ser + não parecer). Em vez de persuadir, este destinador interpreta, na fase final da narrativa, o sentido adotado pelo sujeito em sua missão de conquista do objeto. Da possibilidade desse reconhecimento por parte do destinador julgador decorrem as medidas de recompensa ou punição social.

Essas etapas narrativas, sucintamente descritas, constituem uma verdadeira gramática textual, com princípios relacionais bem-engendrados e investimentos semânticos (valores e modalidades) de caráter universal e abstrato. O desenvolvimento desses instrumentos formais pela semiótica tem apresentado resultados bastante consistentes, sobretudo para a descrição dos textos figurativos e polifónicos.

\section{Um Exemplo}

Podemos pensar na letra da canção Sampa, de Caetano Veloso. em que, em meio a inúmeras citações e remissões a outras esferas 
discursivas, surgem duas vozes principais que congregam esses elementos aparentemente dispersos sob a ordenação de funções narrativas definidas c logicamente dispostas.

"Alguma coisa acontece no meu coração

Que só quando cruza a Ipiranga e a Avenida São João

$\dot{E}$ que quando eu cheguei por aqui eu nada entendi

Da dura poesia concreta de tuas esquinas

Da deselegância discreta de tuas meninas

Ainda não havia para mim Rita Lee a tua mais completa tradução

Alguma coisa acontece no meu coração

Que só quando cruza a Ipiranga e a Avenida São João

Quando te encarei frente a frente não vi o meu rosto

Chamei de mau gosto o que vi de mau gosto mau gosto

É que Narciso acha feio o que não é espelho

E a mente apavora o que ainda não é mesmo velho

Nada do que não era antes quando não somos mutantes

Efoste um difícil começo afasto o que não conheço

E quem vem de outro sonho feliz de cidade

Aprende depressa a chamar-te de realidade

Porque és o avesso do avesso do avesso do avesso

Do povo oprimido nas filas, nas vilas, favelas

Da força da grana que ergue e destrói coisas belas

Da feia fumaça que sobe apagando as estrelas

Eu vejo surgir teiis poetas de campos e espaços

Tuas oficinas de florestas teus deuses da chuva

Panaméricas de Africas utópicas, túmulo do samba

Mas possivel novo Quilombo de Zumbi

E os Novos Baianos passeiam na tua garoa

E novos baianos te podem curtir numa boa."

A primeira voz pertence a um actantc em fase passional, com seu vínculo objetai dcscontinuizado em razão de uma carência modal: o /saber/ e, por extensão, o /crer/. Falta ao sujeito que figurativamente chega a São Paulo elementos para que possa decifrar os valores positivos da cidade. Entretanto, o enunciador dessa canção se desdobra em outra voz 
Luiz Tatit

que tem condições de avaliar com onisciência toda a trilha percorrida pelo primeiro sujeito. Situada numa etapa final do processo narrativo, essa voz desempenha a função sintáxica de destinador julgador que desvenda todos os elos contínuos da relação objetai, disfarçados em formas descontínuas. Assim, por exemplo, no verso "li que quando eu cheguei por aqui eu nada entendi " ouvimos a voz do sujeito passional, desfalcado da modalidade do /saber/, mas ouvimos também a voz do destinador julgador que diz, em segundo plano, que há algo a ser entendido. Na frase "Da dura poesia concreta de tuas esquinas " sentimos, com o sujeito, a aridez e a invulnerabilidde da estética paulistana mas, ao mesmo tempo, pelo destinador julgador, temos as decorrências sensíveis dessa aparente aspereza na expressão da poesia concreta. Esta não pode fazer parte do universo restrito do ator recém-chegado mas pode ser aludida por quem detém a perspectiva geral do processo. $\mathrm{Na}$ frase "Da deselegância discreta de tuas meninas" "deselegância" parece retratar a impressão direta do primeiro sujeito, enquanto "discreta "já reflete uma certa ponderação feita de outra instância. Em "Ainda não havia para mim Rita Lee a tua mais completa tradução " além da referência à cantora cuja existência representa, em si, uma análise de São Paulo (do ponto de vista do destinador, portanto), temos também o simples desamparo do sujeito que não dispõe de qualquer ferramenta para destrinçar os enigmas da cidade (TATIT, 1996: 286).

Pelo enfoque do destinador julgador podemos avaliar o estado do sujeito passional que não encontra na nova cidade os valores cultivados em sua terra natal. O reconhecimento de novos valores depende de um contrato com novos destinadores encarregados de novas estratégias persuasivas. Não tendo como se instruir para completar sua missão, o sujeito passa a rejeitar o objeto, gerando o que se pode chamar de relação objetai: "Ouando te encarei frente a frente não vi o meu rosto / Chamei de mau gosto o que vi de mau gosto mau gosto"

A dcscontinuidade com relação ao objeto reflete' ' uma descontinuidade transcendente entre destinador persuasivo c destinatário-sujeito. Enquanto a primeira fase de relação contratual não se firmar, a segunda também estaciona e a narrativa não progride. À medida que a 
canção evolui, a voz do sujeito passional vai cedendo espaço à voz do destinador julgador e, nessa transição, os valores expostos no modo do /parecer/ passam a coexistir com outros, até então camuflados, resultantes do modo do /ser/- "Do povo oprimido nas filas, nas vilas, favelas.../ Eu vejo surgir leus poetas../"

O tempo da própria canção ć suficiente para que o sujeito passional c o dcstinador-julgador entrem em sincretismo tendo como base categorial o ator-enunciador que, ao final, exibe todo o seu saber a respeito dos percursos pregressos. Agora, aquelas primeiras pinceladas da presença do discurso de outrem ("poesia concreta" "Rita Lee") ganham sua verdadeira dimensão ao lado de uma intensa polifonia que revela as diversas áreas da cultura freqüentadas pela biografia do enunciador: "campos e espaços" (referência aos irmãos Augusto e Haroldo de Campos e à ordem espacial explorada pela poesia concreta; "oficinas " (Teatro Oficina que em 1967 lançou a peça tropicalista $O$ Rei da Vela); "túmulo do samba " (famosa expressão de Vinícius de Morais a respeito de São Paulo); Zumbi (peça encenada pelo Teatro de Arena) etc. (TATIT, 1996: 296-7).

Tudo isso, porém, surtiria bem menos efeito se não apresentasse um papel decisivo na resolução narrativa do texto integral. Ora, logo após a revelação dos personagens c dos eventos ocultos da cidade, os valores contínuos são reencontrados c o sujeito, na figura dos "novos baianos", integra-se plenamente no objeto. Cabe à função de destinador julgador restabelecer a ordem lógica da narrativa e interpretar, de maneira coerente, o percurso do sujeito que abandona os valores descontínuos e disfóricos em nome das relações conjuntivas c eufóricas. Esta última estrofe celebra, na realidade, a revelação dos destinadores persuasivos, de todas as entidades que instruíram o sujeito para que pudesse reconhecer e decifrar o seu objeto. É da continuidade entre destinador e destinatário, de sua relação contratual, que decorre a transferência do /saber/ entre esses actantes e a possibilidade de uma compreensão plena do objeto. E de tudo isso resulta a sanção positiva que reconhece a integração completa da cultura baiana no universo paulistano: "E os Novos Baianos passeiam na sua garoa / E novos baianos te podem curtir numa boa" 


\section{Luiz Tatit}

\section{Bibliografia}

BARROS, D. L. P. (1988). Teoria do discurso - fundamentos semióticos. São Paulo, Atual.

BENVENISTE, E. (1976). Os níveis da análise lingüística. In: Problemas de lingüistica geral. São Paulo, Companhia Editora Nacional/ EDUSP.

BRANDÃO, H. (1991). Introdução à análise do discurso. Campinas, UNICAMP.

COQUET, J. C. (1982). Sémiotique - École de Paris. Paris, Hachette.

DUCROT, O. (1987). O dizer e o dito. Campinas, Pontes.

GREIMAS, A. J. (1974). L'Énonciation. Significação, Ribeirão Preto, Centro de Estudos Semióticos, n. 1.

. (1981). De la colcre. 'Actes Sémiotiques - Documents, Paris, EHESS, CNRS, n. 27.

(1983). Du sens II. Paris, Seuil.

GREIMAS, A. J. e COURTÉES, J. (1979). Sémiotique. Dictionnaire raisoniné de la théorie du Langage. Paris, Hachette.

HAMMAD, M. (1983). Renonciation: procès et système. Langages - la mise en discours, Paris, Larouse, n. 70.

LANDOWSKI, E. (1983). Simulacres en construction. Langages, Paris, Larousse, n. 70.

(1983). De quelques conditions sémiotiques de l'interaction. Actes Sémiotiques-Documents, Paris, EHESS, CNRS, n. 50.

MAINGUENEAU, D. (1989). Novas tendências em análise do discurso. Campinas, UNICAMP, Pontes.

PÊCHEUX, M. ( 1990). O discurso - estrutura ou acontecimento. Campinas, Pontes.

TATIT, L. (1996). O cancionista: composição de canções no Brasil. São Paulo, EDUSP.

ZILBERBERG, C. (1988). Raison et poétique du sens. Paris, PUF. 